\title{
Pharmacognostical characterization and in vitro antioxidant activity of Acacia pennata (L.) Willd. leaves: A Southeast Asian medicinal plant
}

\author{
James H. Zothantluanga, Ngurzampuii Sailo, Arpita Paul, Anshul Shakya* \\ Department of Pharmaceutical Sciences, Faculty of Science and Engineering, Dibrugarh University, Dibrugarh 786004, Assam, India
}

\begin{abstract}
Pre-defined analytical features of a plant are used as a reference to aid in accurate identification, proper standardization, and quality control. However, no systematic work on the leaves of $A$. pennata is available for reference to check its authenticity, purity, and quality. Therefore, the study was aimed to develop pharmacognostic parameters using standard guidelines. The work provides macroscopic, qualitative and quantitative microscopic, physicochemical parameters, chromatographic fingerprint profile, and in-vitro antioxidant activity of $A$. pennata. Preliminary phytochemical screening and thin-layer chromatography hints the presence of steroids and glycosides along with polyphenolic compounds viz. phenols and flavonoids. Quantification of polyphenolic phytoconstituents and assessment of invitro antioxidant activity of the methanolic extract was done. The current communication offers referential knowledge on the analytical and diagnostic features for accurate taxonomical identification, proper characterization and will also help in the establishment of a pharmacognostic monograph of $A$. pennata for effective quality control.
\end{abstract}

Keywords: Acacia pennata, antioxidant, pharmacognostic parameters, polyphenols, thin layer chromatography.

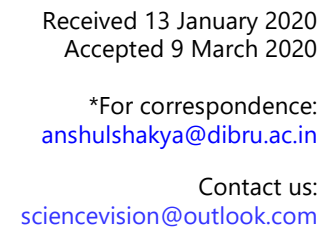

\section{Introduction}

Acacia pennata (L.) Willd. (A. pennata) belonging to the family 'Mimosaceae' is a thorny shrub generally found in Southwest China, India, Myanmar, Bangladesh, Bhutan, Sri Lanka, and Thailand within the range of $800-1500 \mathrm{~m}$ above the sea level. ${ }^{1} A$. pennata, also known as climbing acacia, is traditionally used for burning urine, bleeding gums, fever, a disorder of the blood, eruption, indigestion, oculopathy, hemorrhoids, bronchitis, asthma, stomach ache, skin burn, wound healing, strengthening of bone, removing fowl's bone in the throat, cholera, headache, snake bite, body pain, biliousness, treating spasm, dysentery, toothache, and flatulence was successfully investigated at the pre-clinical level for its anti-herpes simplex virus, anti -inflammatory, anti-nociceptive, anti-oxidant, antifungal, anti-cancer, anti-diabetic, anthelmintic, antiAlzheimer, anti-hyperlipidaemic, larvicidal, pupicidal, anti-lice and anti-HIV activity. ${ }^{2}$

However, the plant is still devoid of qualitative and quantitative parameters like stomatal number, stomatal index, palisade ratio, vein termination 
number, vein islet number, fluorescence analysis of powdered drug, ether soluble extractive, chloroform soluble extractive and fluorescence analysis of extracts. Thus, the study was aimed to develop the necessary pharmacognostic parameters and improve the existing herbal monograph for $A$. pennata based on its pharmacognostical features. As per the results obtained from preliminary phytochemical screening and thin layer chromatography (TLC), total phenolic and flavonoid content of the methanolic leaves extract were quantified. Upon confirming the presence of a free radical scavenging class of phytocompounds, the antioxidant activity of the plant was evaluated in-vitro using 2, 2-diphenyl-1picrylhyrazyl and nitric oxide scavenging techniques.

\section{Materials and Methods}

\section{Collection of plant material}

As per the World Health Organization guidelines on good agricultural and collection practices for medicinal plants (WHO-GACPMP), fresh leaves of the plant material were manually collected under the supervision of a local knowledgeable guide from Saikhamakawn, Aizawl, Mizoram, India. ${ }^{3}$

\section{Taxonomic identification and authentication}

As per WHO-GACPMP, a prepared herbarium along with a new batch of freshly collected plant specimens was taken for taxonomic identification and was authenticated at the Department of Botany, Pachhunga University College, Aizawl, Mizoram, India. A voucher specimen (DU/PSC/HRB/AS01/2019) was preserved in the research lab (AS), Department of Pharmaceutical Sciences, Dibrugarh University for future reference. ${ }^{3}$

\section{Equipment, chemicals and reagents}

The types of equipment used for the study were

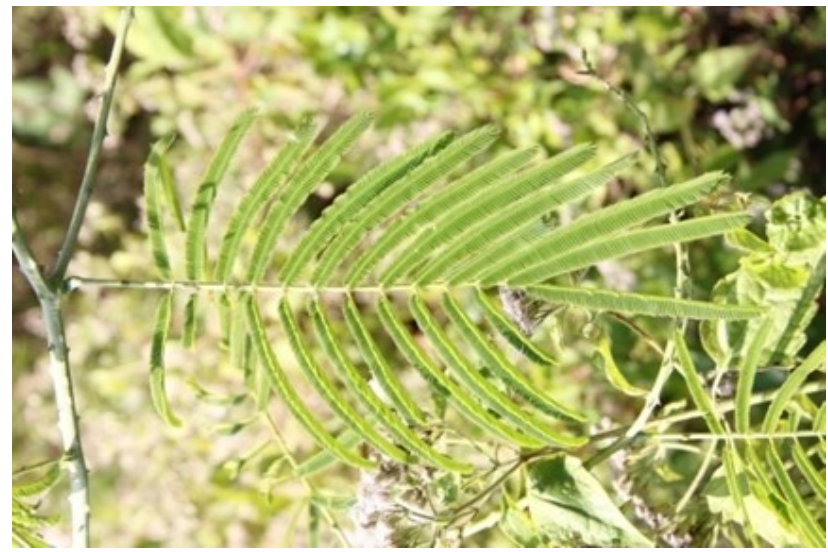

Figure1 | Leaf of $A$. pennata.
UV spectrophotometer (Shimadzu); UV scanner (CAMAG); projection microscope (Zeiss); hot air oven (Narang Scientific Works Pvt. Ltd.); muffle furnace (Lab Tech); water bath (Riviera Glass Pvt. Ltd.) and a desiccator (Genaxy). Standard references and reagents were purchased from Sigma-Aldrich, India. All the solvents used were of analytical grade.

\section{Processing of the plant material}

The crude drug shade dried at room temperature was successively extracted via maceration and percolation using petroleum ether, chloroform, ethyl acetate, and methanol. The extracts obtained from both the extractive methods were mixed and were collected in a glass petridish and stored in adesiccator. ${ }^{4}$ Fresh leaflets were also treated with chloral hydrate solution for microscopic studies. ${ }^{5}$

\section{Macroscopic evaluation}

The leaves of $A$. pennata were manually investigated for its organoleptic features. ${ }^{5}$

\section{Stomatal number and stomatal index}

A leaflet was mounted on a glass slide and a drop of glycerine was added. The slide was observed under a projection microscope at 40X magnification. The type of stomata was identified. The stomata's within four separate $150 \mathrm{sq} \mu \mathrm{m}$ and those with half of its area inside the square were counted. The total number of epidermis on the upper surface and lower surface were also counted in each square. The stomatal index was then calculated using the formula. ${ }^{5}$

$$
\mathrm{I}=\frac{S}{E+S} \times 100
$$

Where I = stomatal index; $\mathrm{S}=$ number of stomata per unit area; $E$ = number of epidermal cells in the same unit area.

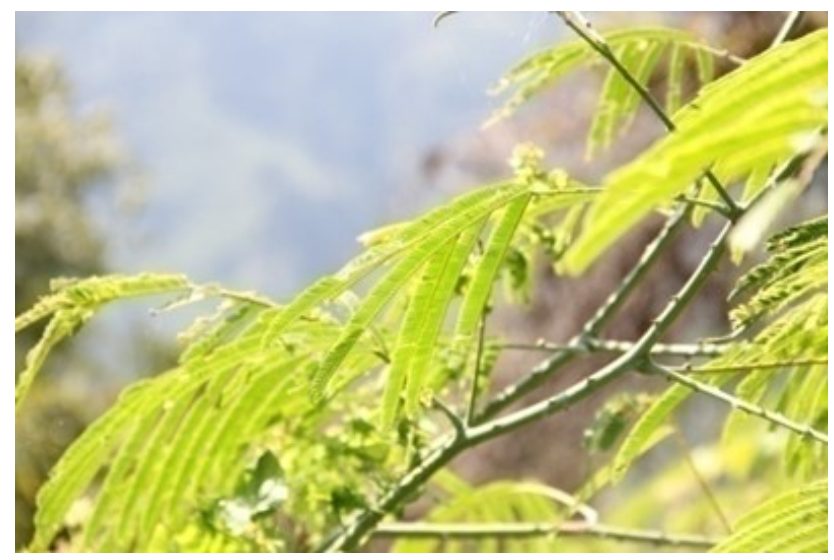

Figure 2 | Leaves and stem of $A$. pennata. 


\section{Palisade ratio}

A leaflet mounted on a glass slide moistened with a drop of glycerine was examined under a projection microscope at $40 \times$ magnification. Palisade cells including those with half of its area within four connected epidermal cells were counted. The average number of palisade cells present under each epidermal cell is taken as the palisade ratio. ${ }^{5}$

\section{Vein islet number and vein termination number}

A drop of glycerine added to the leaflet placed on a glass slide was observed under a projection microscope at $10 \times$ magnification. Vein islets and vein terminations within an area of four different 600 sq $\mu \mathrm{m}$ were counted and recorded. ${ }^{5}$

\section{Powdered microscopy}

A pinch of the powdered crude drug was placed on a glass slide. After staining with appropriate reagents, a cover glass was placed on top of the mixture and the slide was observed at $10 x$ and $40 x$ magnifications. ${ }^{6,7}$

\section{Fluorescence analysis of powdered drug}

The powdered drug placed on a glass slide was subjected to different reagents which were then observed under daylight, $254 \mathrm{~nm}$ and $366 \mathrm{~nm} .{ }^{8,9}$

\section{Total ash value}

The powdered drug $(2 \mathrm{~g})$ placed in a silica crucible was heated in a muffle furnace at a temperature of $450^{\circ} \mathrm{C}$ till carbon-free white ash was obtained which was then cooled in a desiccator. ${ }^{5}$

$$
\text { Total ash value }(\% \mathrm{w} / \mathrm{w})=\frac{Y-X}{Z} \times 100
$$

Where, $X=$ weight of empty crucible; $Y=$ weight of empty crucible and ash; $Z$ = weight of the powdered crude drug.

\section{Acid-insoluble ash and water-soluble ash}

The total ashes obtained previously were used for determination of acid-insoluble as well as watersoluble ash wherein the ashes were boiled separately with $1 \mathrm{M} \mathrm{HCl}(25 \mathrm{ml})$ and distilled water $(25 \mathrm{ml})$ for 5 minutes respectively. Insoluble matters were collected on ash-less filter papers and were rinsed with $5 \mathrm{ml}$ of boiled distilled water and were filtered. The ash-less filter paper containing the acidinsoluble ash and water-soluble ash were kept in a muffle furnace at $450^{\circ} \mathrm{C}$ for 12 hours. The ashes were cooled in a desiccator. ${ }^{5}$

$$
\text { Ash value }=(\% \mathrm{w} / \mathrm{w})=\frac{Y-X}{Z} \times 100
$$

Where, $X=$ weight of empty crucible; $Y=$ weight of empty crucible and ash; $Z$ = weight of the powdered crude drug.

\section{Extractive value}

The crude drug $(5 \mathrm{~g})$ placed in a conical flask was macerated with $100 \mathrm{ml}$ methanol for 6 hours with frequent shaking and then kept idle for 18 hours. The filtrate $(25 \mathrm{ml})$ was transferred to previously weighed petridish, evaporated using a water bath and further dried in a hot air oven at $105^{\circ} \mathrm{C}$ for 6 hours. It was cooled in a desiccator and the same process was repeated using water, chloroform and petroleum ether. ${ }^{10}$

$$
\text { Extractive value }(\% \mathrm{w} / \mathrm{w})=\frac{Y-X}{Z} \times 100
$$

Where, $X=$ weight of empty petri dish; $Y=$ weight of empty petri dish and extract; $Z=$ weight of the powdered crude drug.

\section{Foreign organic matter}

The crude drug (100 g) was spread evenly with no overlapping. Any foreign organic matter visible to the naked eye was handpicked and removed. A simple magnifying glass was also used for the said purpose. The crude drug was weighed and the presence of foreign organic matter was calculated in percentage. $^{10}$

$$
\text { Foreign organic matter }(\% \mathrm{w} / \mathrm{w})=\frac{Y-X}{Z} \times 100
$$

Where, $X=$ initial weight of crude drug; $Y=$ final weight of the crude drug.

\section{Loss on drying}

The air-dried crude drug $(1.5 \mathrm{~g})$ placed on a porcelain dish was subjected to a temperature of $105^{\circ} \mathrm{C}$ for 30 minutes. The loss in weight is recorded as the moisture lost due to drying. ${ }^{5}$

\section{Fluorescence analysis of extracts}

The fluorescence of plant extracts was analyzed under daylight, $254 \mathrm{~nm}$ and $366 \mathrm{~nm}$ by making a slight variation in the method followed for the fluorescence analysis of powdered drug. ${ }^{8,9}$

\section{Phytochemical screening}

The plant extracts were screened qualitatively to check the presence for different classes of phytoconstituents using different chemical tests. ${ }^{5}$ 


\section{Thin layer chromatography}

As per the results obtained from phytochemical screening, TLC for phenols, flavonoids, glycosides and steroids were performed using crude TLC plates prepared on a regular glass slide $\left(3^{\prime \prime}\right.$ by $\left.1^{\prime \prime}\right)$ with silica gel G. The mobile phase for eluting phenols, flavonoids, glycosides and steroids were ethyl acetate : benzene (5:5); toluene : ethyl acetate : water : formic acid (8.5:0.5:0.5:0.5); methanol : water : chloroform (6.5:2.5:0.4); and toluene : ethyl acetate (9.3:0.7) respectively. Phenols and flavonoids were detected by spraying sulphuric acid while glycosides and steroids were detected using the iodine chamber. The retention factor $\left(R_{f}\right)$ value was calculated using the formula., ${ }^{4,11}$

$$
R_{f}=\frac{\text { Distance travelled by solute }}{\text { Distance travelled by solvent }}
$$

\section{Total phenolic content}

The total phenolic content of the methanolic extract of $A$. pennata (MEAP) was quantified using Folin-Ciocalteu's method. A stock solution of gallic acid and sample $(100 \mu \mathrm{g} / \mathrm{ml})$ prepared using methanol was diluted to obtain concentrations of 10 , $20,40,60,80$, and $100 \mu \mathrm{g} / \mathrm{ml}$ respectively. FolinCiocalteu's reagent $(100 \mu \mathrm{l})$ and distilled water $(4 \mathrm{ml})$ were added to each dilution. After 5 minutes, 20\% $\mathrm{Na}_{2} \mathrm{CO}_{3}(1.5 \mathrm{ml})$ was added to each dilution and the volumes were made up to $10 \mathrm{ml}$ using distilled water. The absorbances were recorded at $760 \mathrm{~nm}$ and the blank was carried out using methanol. The result was expressed as $\mathrm{mg}$ of gallic acid equivalent weight $(\mathrm{GAE}) / \mathrm{g}$ of the extract. ${ }^{12,13}$

\section{Total flavonoid content}

Aluminium chloride colorimetric assay method was used for quantifying the total flavonoid content of the MEAP. A stock solution of quercetin and sample $(100 \mu \mathrm{g} / \mathrm{ml})$ prepared using methanol was diluted to obtain concentrations of $10,20,40,60,80$, and $100 \mu \mathrm{g} / \mathrm{ml}$ respectively. Five minutes after the addition of distilled water $(4 \mathrm{ml})$ and $5 \%$ sodium nitrite solution $(0.3 \mathrm{ml}) ; 10 \%$ aluminium chloride $(0.3$ $\mathrm{ml}$ ) was added. After adding $1 \mathrm{M} \mathrm{NaOH}$ solution (2 $\mathrm{ml}$ ) at the sixth minute, the volumes were made up to $10 \mathrm{ml}$ using distilled water. The absorbances were recorded at $510 \mathrm{~nm}$ and the blank was carried out using methanol. The result was expressed as $\mathrm{mg}$ of quercetin equivalent weight $(\mathrm{QE}) / \mathrm{g}$ of the extract. ${ }^{14,15}$

\section{2, 2-Diphenyl-1-picrylhyrazyl (DPPH) radical scavenging activity}

A stock solution $(100 \mu \mathrm{g} / \mathrm{ml})$ of the MEAP prepared using methanol was processed to obtain
$20,40,60,80,100$, and $120 \mu \mathrm{g} / \mathrm{ml}$ respectively. A volume of $2 \mathrm{ml}$ of $0.1 \mathrm{mM}$ DPPH solution was added to each dilution. After 30 minutes of incubation in a dark chamber, the absorbances were recorded at $517 \mathrm{~nm}$. The blank was performed using methanol and DPPH (1:2). Quercetin (20-120 $\mu \mathrm{g} / \mathrm{ml})$ was used as the standard antioxidant. The percentage inhibition was calculated. ${ }^{16}$

$$
\% \text { inhibition }=\frac{A(\text { blank })-A(\text { sample })}{A(\text { blank })} \times 100
$$

\section{Nitric oxide radical scavenging activity}

A stock solution $(100 \mu \mathrm{g} / \mathrm{ml})$ of the MEAP prepared using methanol was processed to obtain $20,40,60,80,100$, and $120 \mu \mathrm{g} / \mathrm{ml}$ respectively. 10 $\mathrm{mM}$ sodium nitroprusside $(0.5 \mathrm{ml})$ in phosphate buffer saline $(\mathrm{pH} 7.4)$ was mixed with $1 \mathrm{ml}$ of different dilutions. It was incubated at $25^{\circ} \mathrm{C}$ for 2 hours. Griess reagent $(1.2 \mathrm{ml})$ was added to each reaction mixture. The absorbance was recorded at $546 \mathrm{~nm}$. The blank was performed using sodium nitroprusside and Griess reagent. Ascorbic acid (20$120 \mu \mathrm{g} / \mathrm{ml}$ ) was used as the standard antioxidant. The percentage inhibition was calculated. ${ }^{17,18}$

$$
\% \text { inhibition }=\frac{A(\text { blank })-A(\text { sample })}{A(\text { blank })} \times 100
$$

\section{Statistical analysis}

Statistical analyses were performed using Microsoft Excel 2006 (Microsoft Corporation) and SPSS software. Linear regression was used to calculate $I C_{50}$ values. The majority of the experiment were carried out and calculated in triplicates except for quantitative microscopic parameters where standard protocols demand a repetition of 4 times. The results were expressed as mean \pm standard deviation of the mean followed by the number of experiments.

\section{Results}

\section{Macroscopic features}

The leaves of $A$. pennata, given in Figures 1 and 2, are bipinnately compound in nature wherein the upper and lower surfaces of the leaves are dark and light green respectively. The length and width of the leaflets are $4-8 \mathrm{~mm}$ and $1 \mathrm{~mm}$ respectively. Though a midrib is slightly prominent towards the edge, a prominent/proper midrib is absent. The petioles (whose length is $1-3 \mathrm{~cm}$ ) and rachis are obscurely prickled. The plant has a peculiar odor and is tasteless at first, followed by a slightly bitter taste.

\section{Microscopic features}

The type of stomata present in $A$. pennata is 

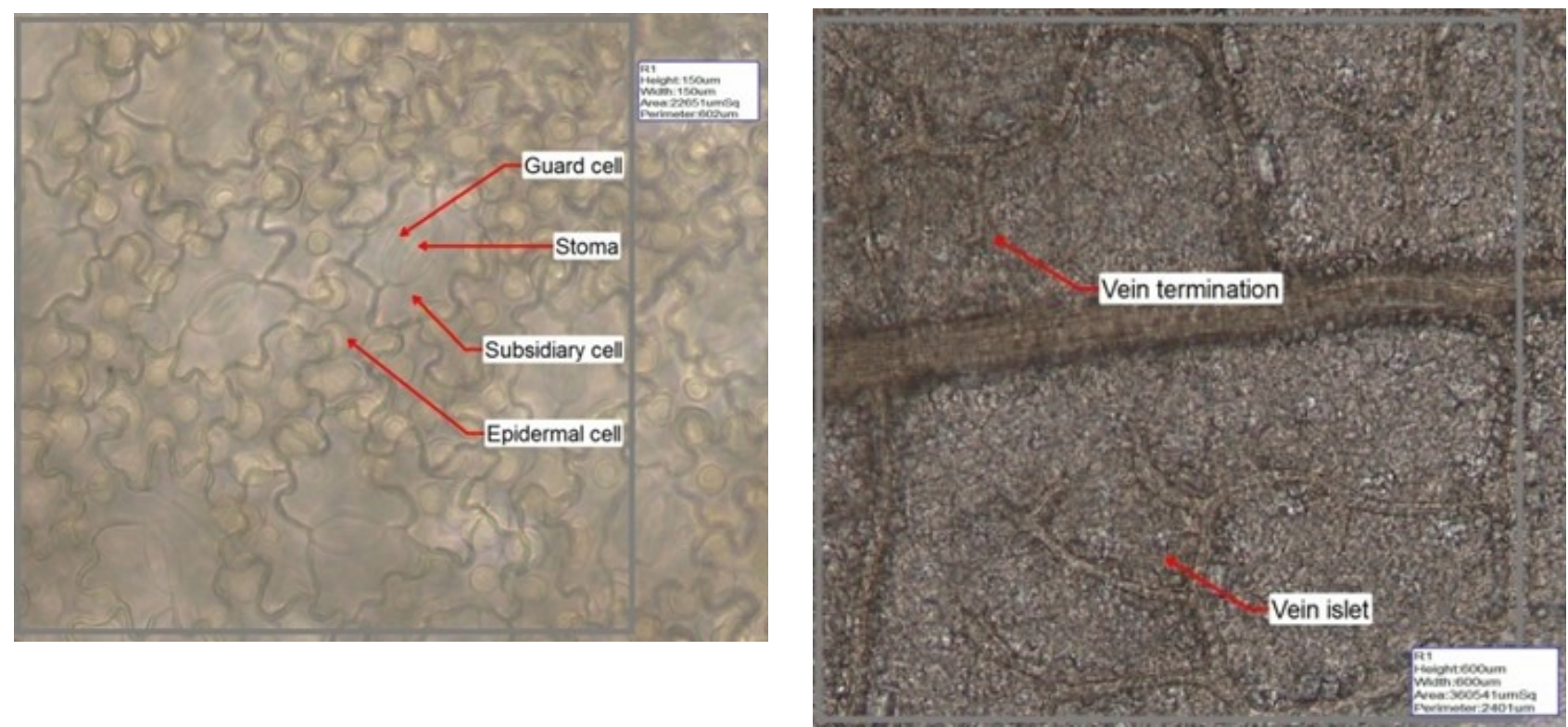

Figure 3 | Paracytic stomata of the leaf of $A$. pennata.

Figure $\mathbf{4}$ | Vein islet and vein termination of the leaf of A. pennata.

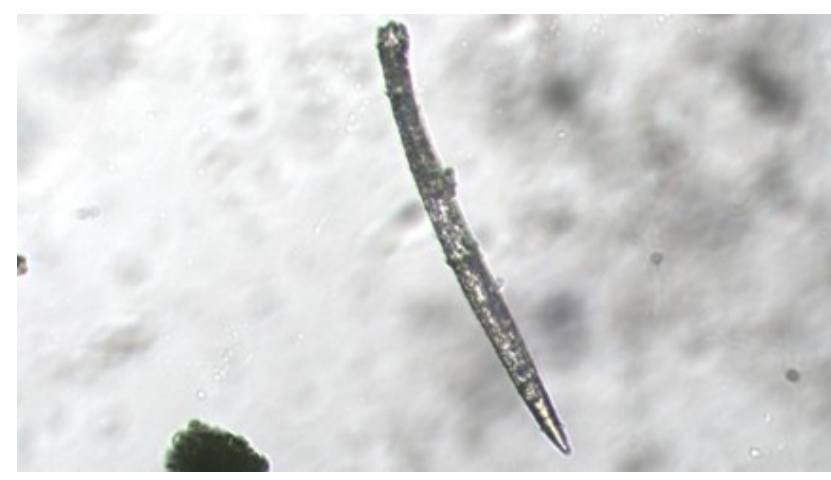

Figure $\mathbf{5}$ | Covering trichome of the leaf of $A$. pennata.

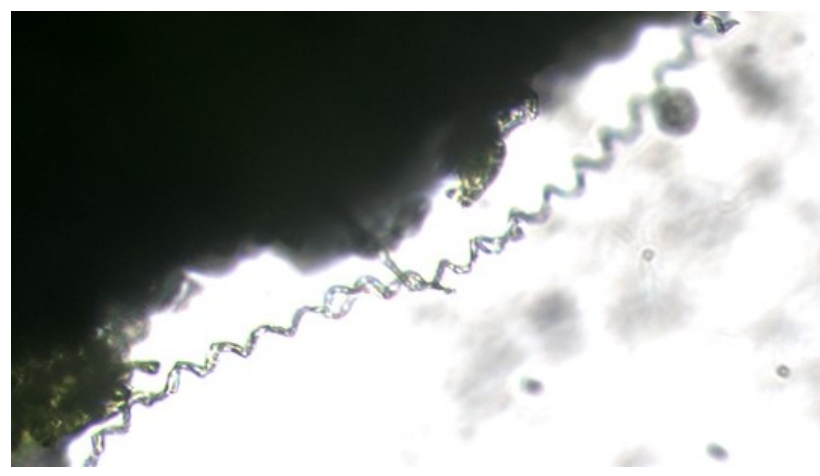

Figure 6 | Spiral vessel of the leaf of $A$. pennata.

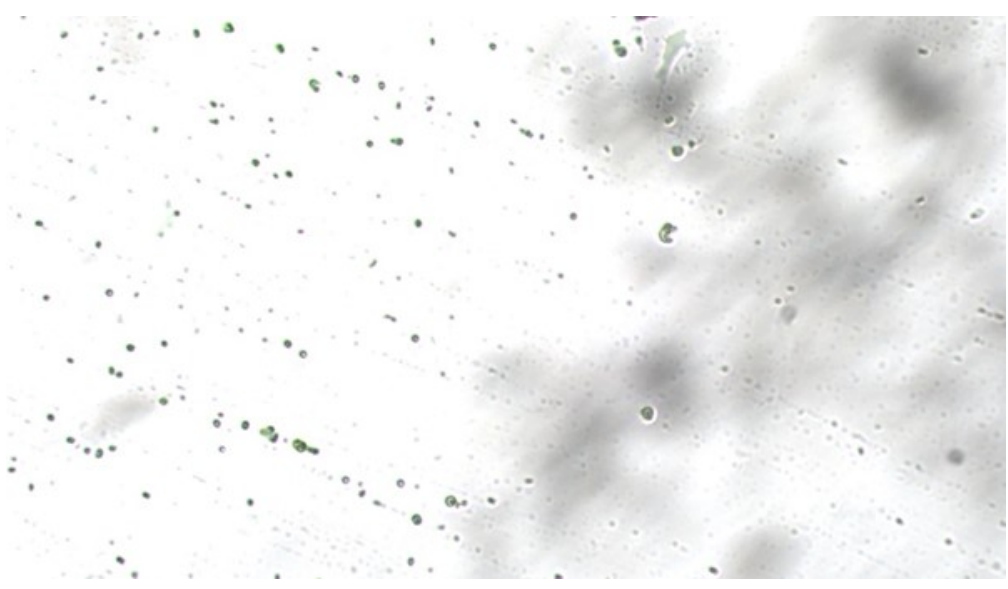

Figure 7 | Starch grains of the leaf of $A$. pennata. 
$\dashv 0.75 \pm 0.96$

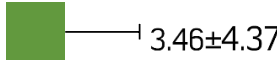

$8.75 \pm 2.06$

$35.6 \pm 3.52$

$3.74 \pm 0.96$

$2.5 \pm 1.29$

$1 \pm 0: 3.75 \pm 0.96$

\begin{tabular}{llllll}
\hline & 10 & 20 & 30 & 40 & 50
\end{tabular}

- Stomatal number (upper epidermis)

- Stomatal index (upper surface)

- Stomatal number (lower epidermis)

- Stomatal index (lower surface)

- Vein islet number

Vein termination number

- Palisade ratio

Figure 8 | Quantitative microscopic features of the leaf of $A$. pennata $(n=4)$.

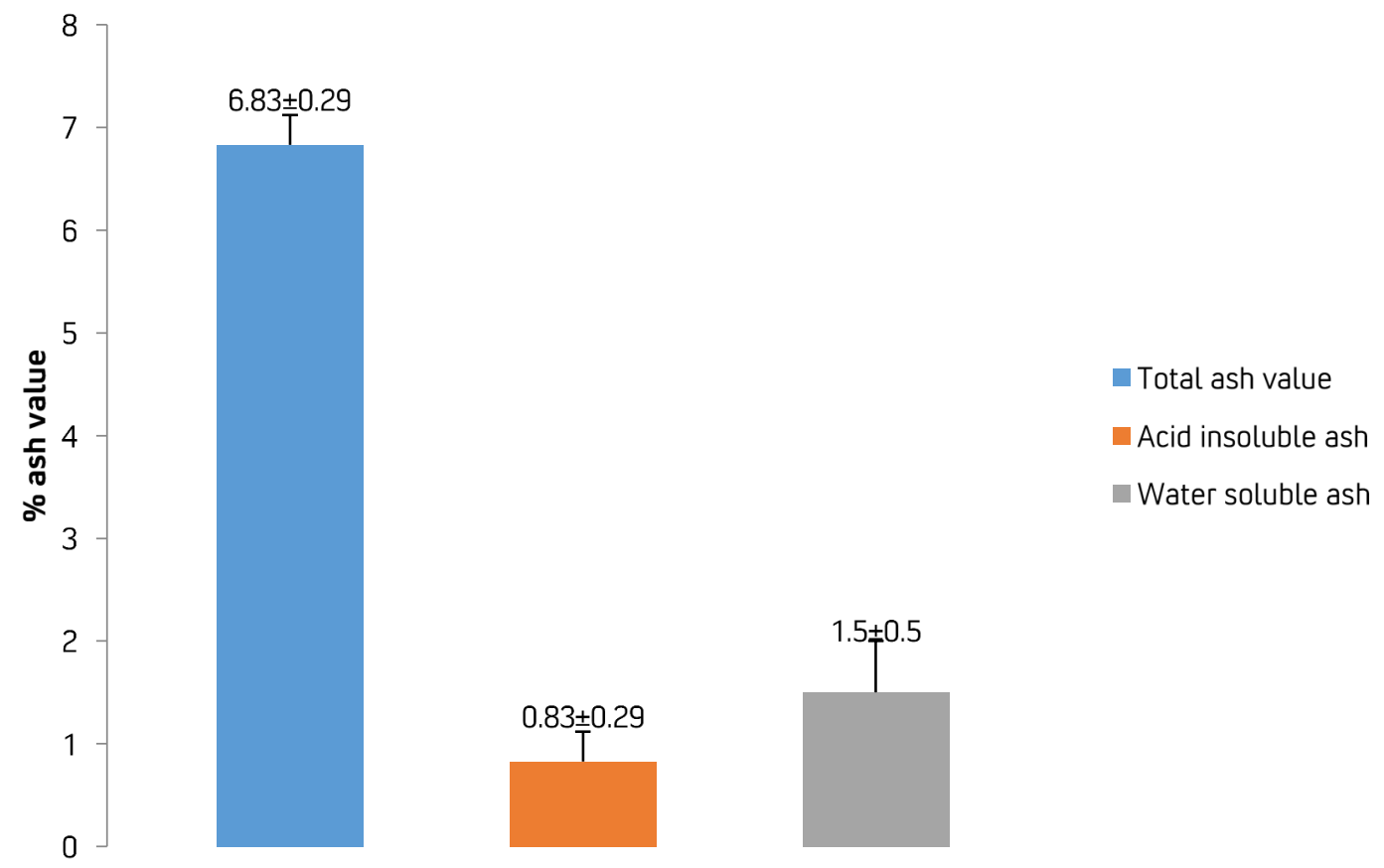

Figure 9 | Ash values of the leaves of $A$. pennata $(n=3)$. 


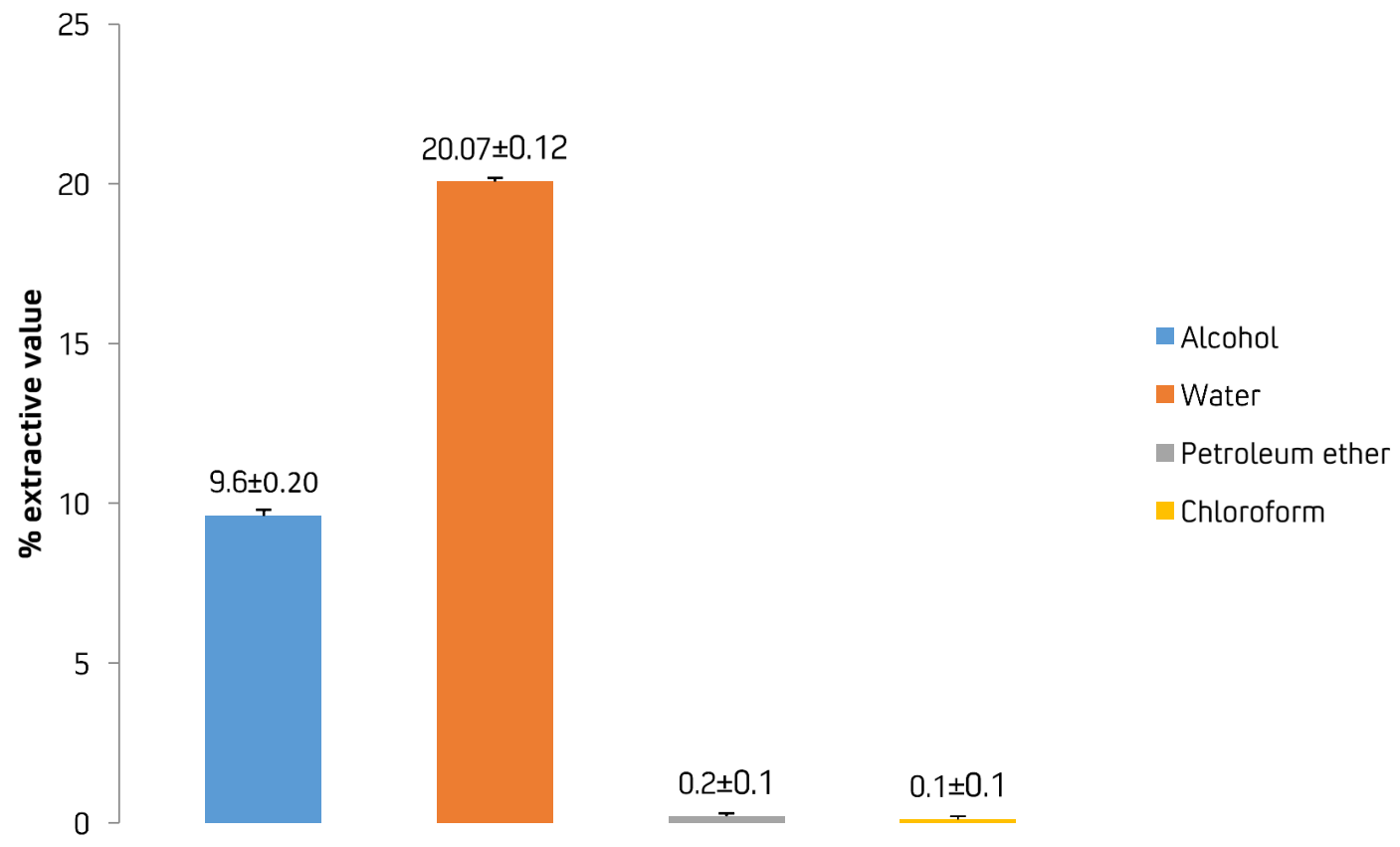

Figure 10 | Total extractive values of the leaves of $A$. pennata $(n=3)$.

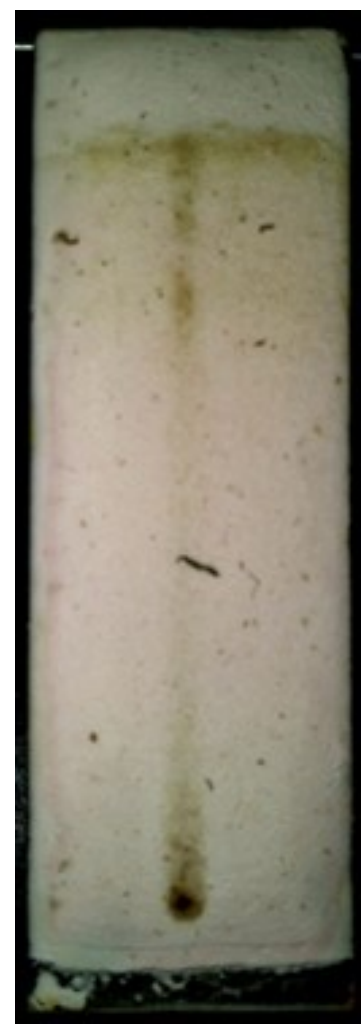

(i)

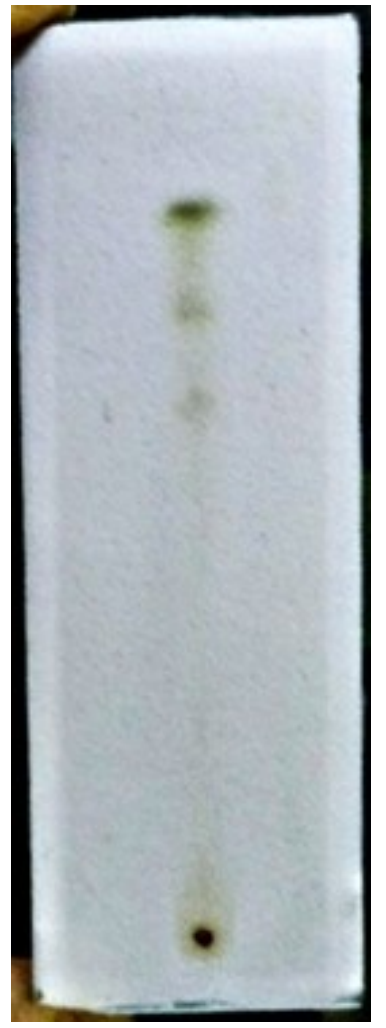

(ii)

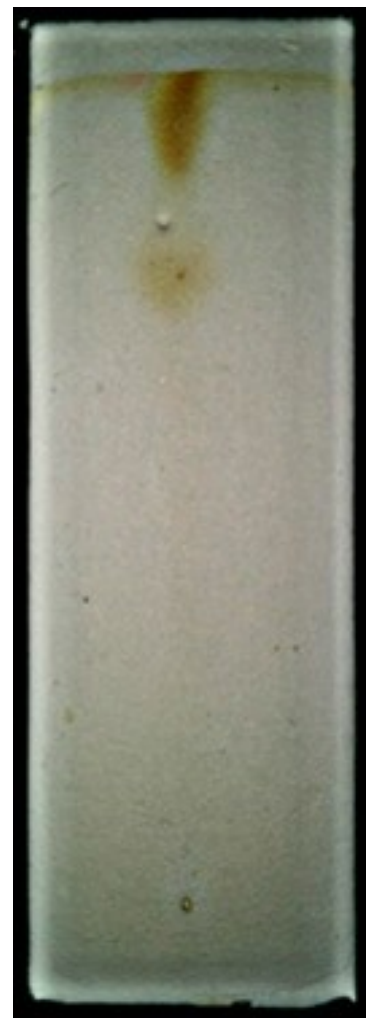

(iii)

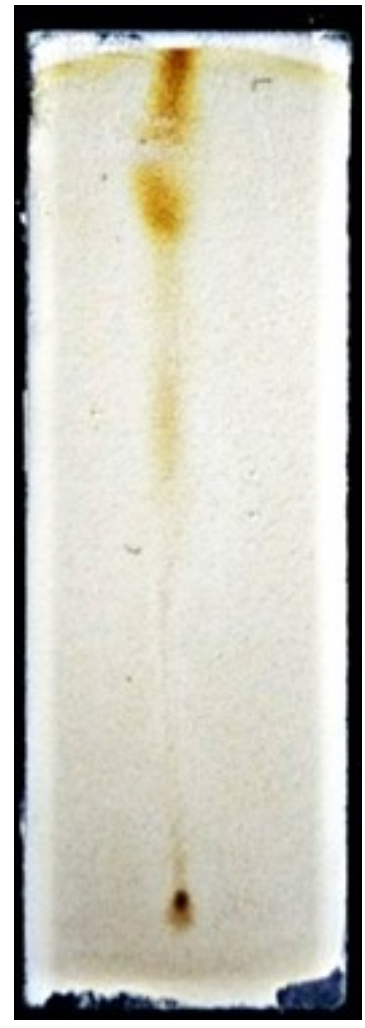

(iv)

Figure 11 | TLC for (i) phenols $\left(R_{f}=0.78\right)$; (ii) flavonoids $\left(R_{f}=0.59,0.77,0.86\right)$; (iii) glycosides $\left(R_{f}=0.72\right)$; (iv) steroids $\left(R_{f}\right.$ $=0.86$ ). 


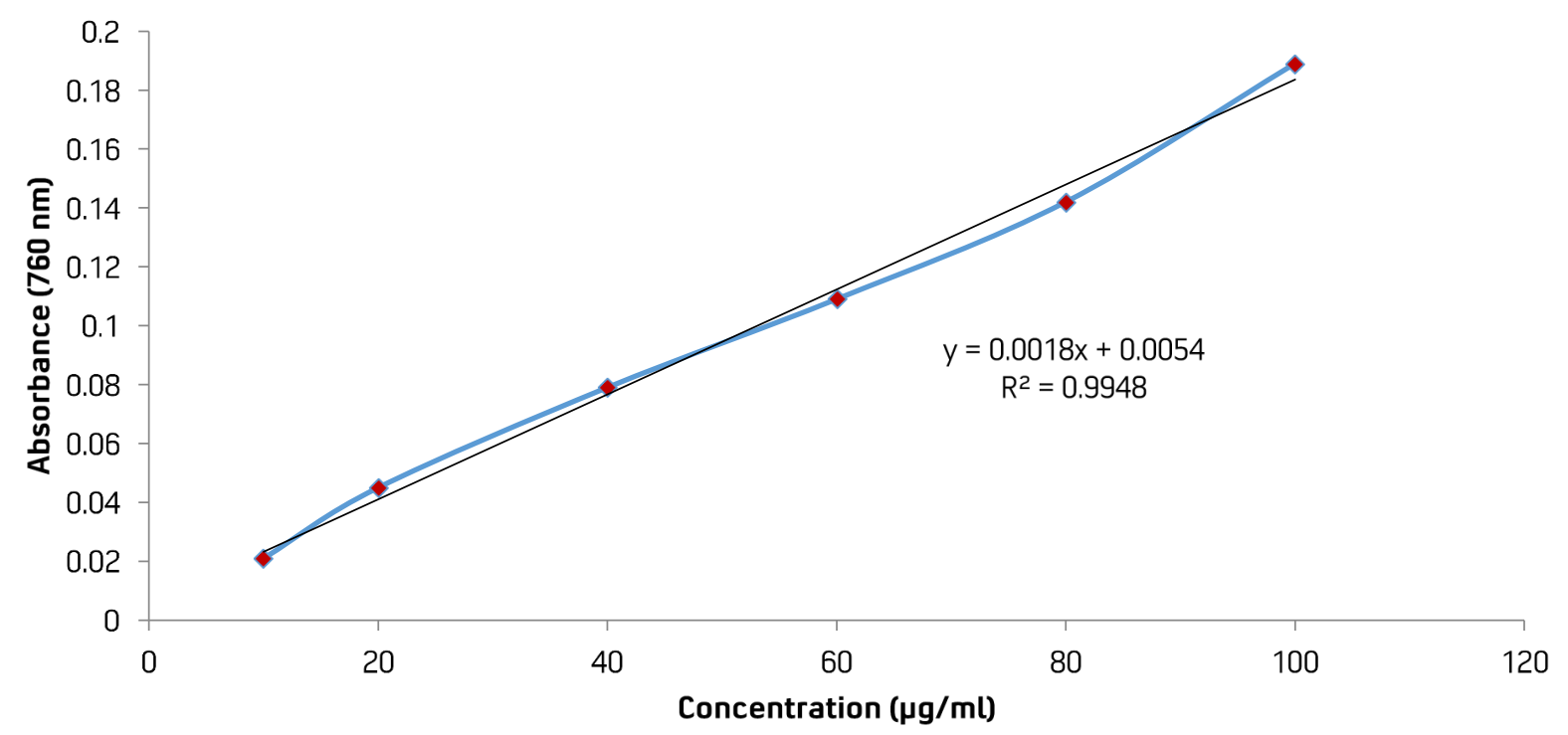

Figure 12 | Calibration curve for total phenolic content.

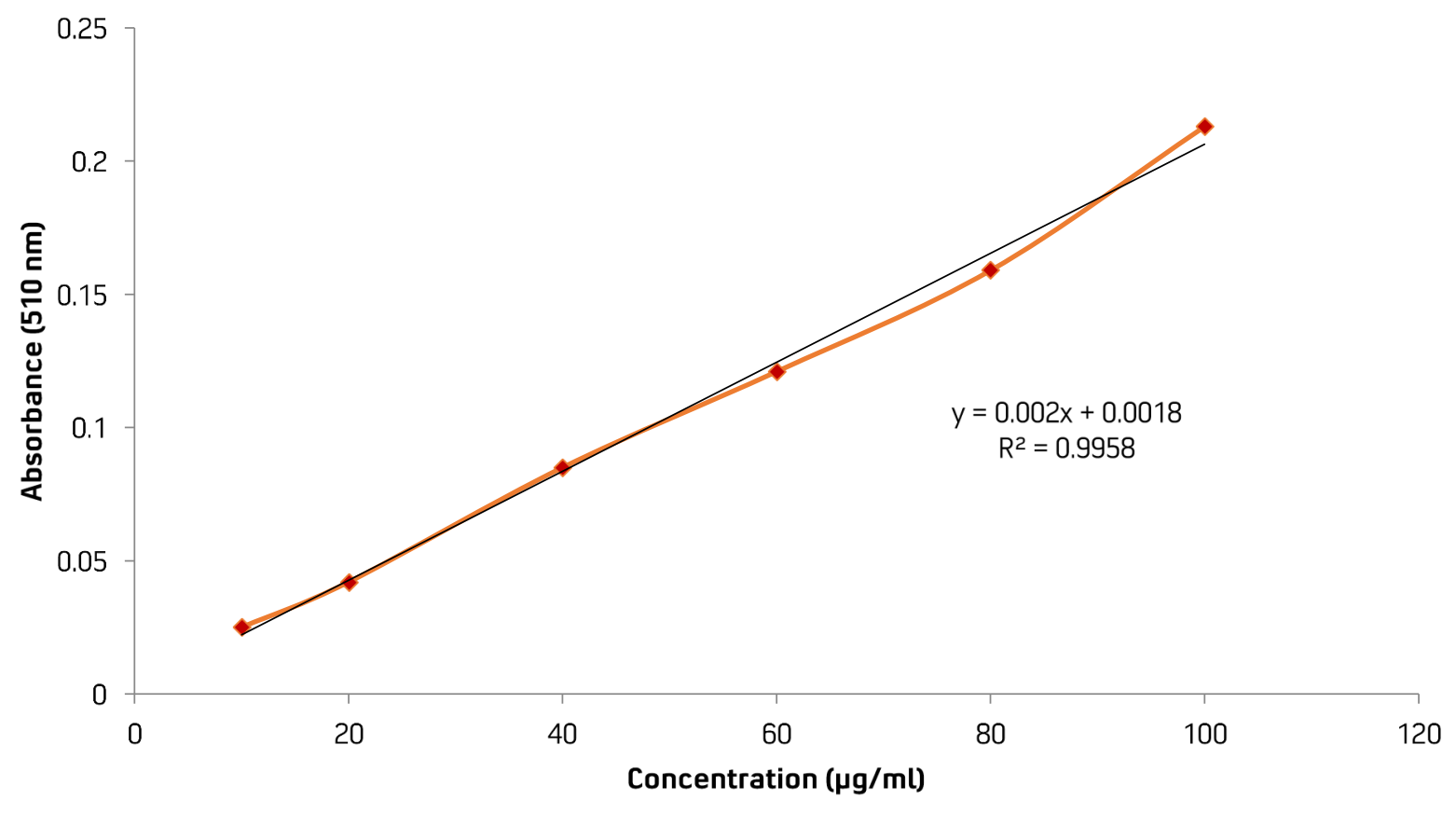

Figure 13 | Calibration curve for total flavonoid content. 


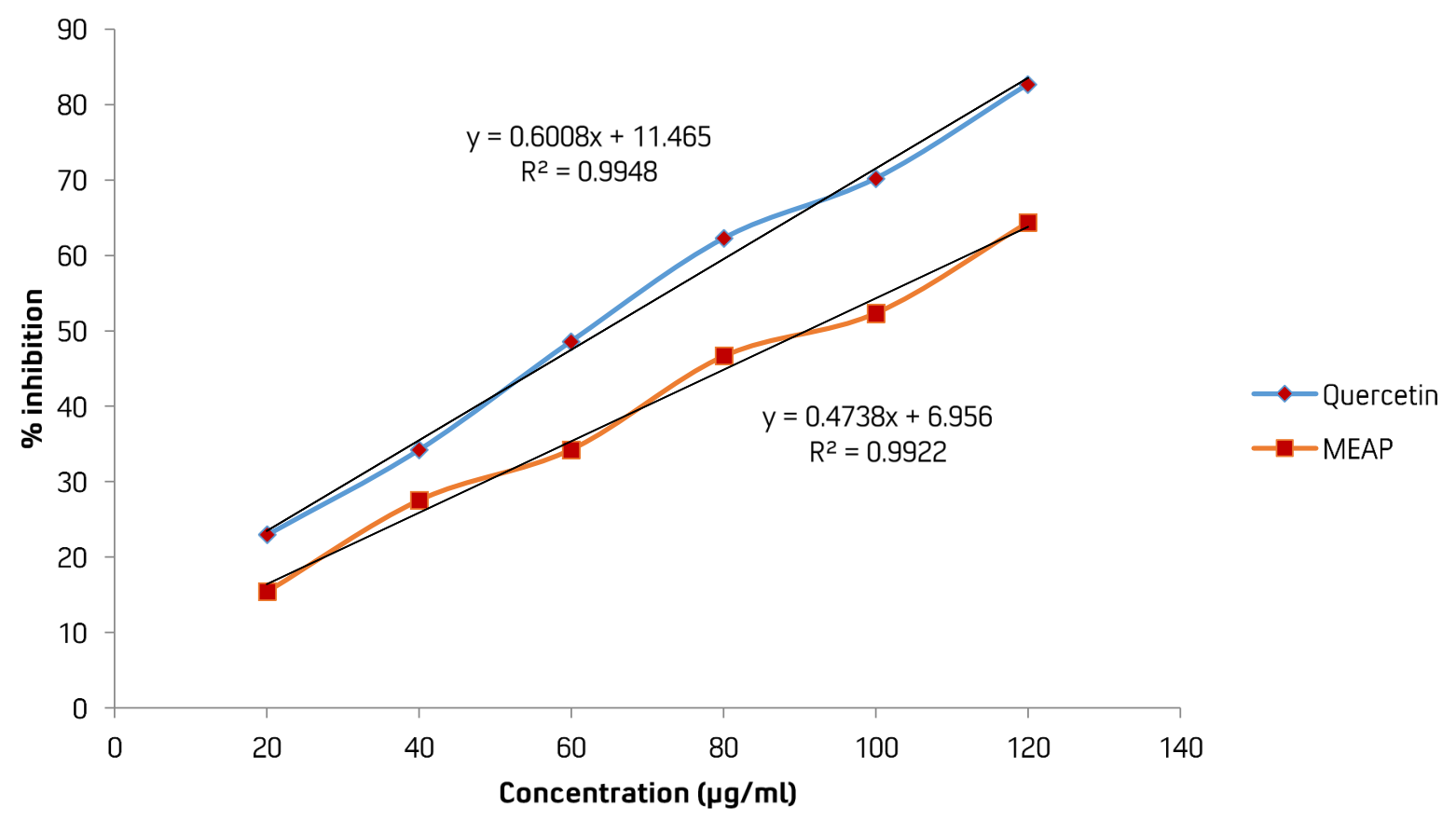

Figure 14 | DPPH radical scavenging activity of quercetin and MEAP.

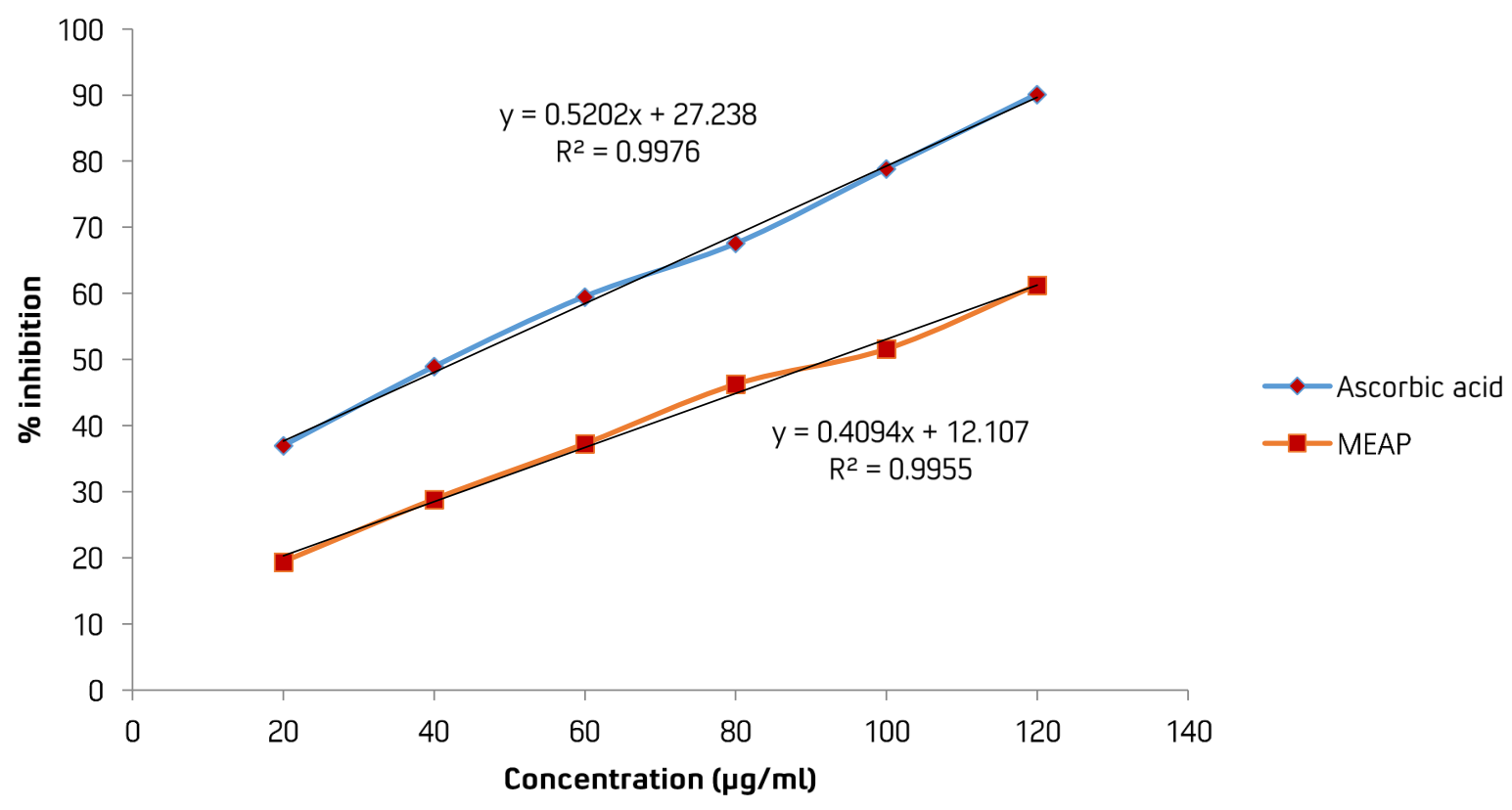

Figure 15 | Nitric oxide radical scavenging activity of ascorbic acid and MEAP. 
Table 1 | Fluorescence analysis of crude powdered leaves of $A$. pennata

\begin{tabular}{|llll}
\hline Powdered drug+ reagent & Daylight & $\mathbf{2 5 4} \mathbf{~ n m}$ & $\mathbf{3 6 6} \mathbf{n m}$ \\
\hline Powdered drug + Methanol & Dark green & No fluorescence & Greenish yellow \\
\hline Powdered drug + Water & Olive green & No fluorescence & Greenish yellow \\
\hline Powdered drug + lodine & Dark yellow & Dark red & Black \\
\hline Powdered drug $+\mathrm{FeCl} 3$ & Yellowish green & Black & Black \\
\hline Powdered drug $+\mathrm{KOH}$ & Bright green & Black & Greenish yellow \\
\hline Powdered drug $+\mathrm{NaOH}$ & Bright green & Dark violet & Dark green \\
\hline Powdered drug $+\mathrm{HCl}$ & Olive green & Black & Black \\
\hline Powdered drug $+\mathrm{HNO}_{3}$ & Reddish brown & Dark violet & Black \\
\hline Powdered drug $+\mathrm{NH}_{3}$ & Olive green & Black & Green \\
\hline Powdered drug + Picric acid & Bright green & Dark green & Black \\
\hline Powdered drug + Glacial acetic acid & Blackish yellow & Black & Greenish yellow \\
\hline
\end{tabular}

Table 2 | Fluorescence analysis of the extracts of $A$. pennata leaves in different solvent systems

\begin{tabular}{lccc}
\hline Extracts & Daylight & $\mathbf{2 5 4} \mathbf{n m}$ & $\mathbf{3 6 6} \mathbf{n m}$ \\
\hline Petroleum ether & Yellow & Dark purple & Bright purple \\
\hline Chloroform & Dark green & Dark purple & Bright purple \\
\hline Ethyl acetate & Dark green & Dark purple & Bright purple \\
\hline Methanol & Dark green & Dark purple & Bright purple \\
\hline
\end{tabular}

Table 3 | Preliminary phytochemical screening of different extracts of the leaves of $A$. pennata

\begin{tabular}{lcccc}
\hline \multicolumn{1}{c}{ Phytocompound } & Petroleum ether & Chloroform & Ethyl acetate & Methanol \\
\hline Carbohydrates & - & - & - & + \\
\hline Proteins & - & - & - & + \\
\hline Steroids & + & - & - & - \\
\hline Flavonoids & - & - & - & + \\
\hline Phenols & - & - & - & + \\
\hline Glycosides & - & - & - & - \\
Alkaloids & - & - & - \\
\hline Saponins & - & & - & + \\
\hline
\end{tabular}

Table 4 | \% inhibition of DPPH radicals by quercetin and $\operatorname{MEAP}(n=3)$

\begin{tabular}{ccc}
\hline $\begin{array}{c}\text { Concentration } \\
(\boldsymbol{\mu g} / \mathrm{ml})\end{array}$ & $\begin{array}{c}\text { Quercetin } \\
(\% \pm \mathrm{SD})\end{array}$ & $\begin{array}{c}\text { MEAP } \\
(\% \pm \mathrm{SD})\end{array}$ \\
\hline 20 & $22.95 \pm 0.10$ & $15.43 \pm 0.27$ \\
\hline 40 & $34.24 \pm 0.21$ & $27.56 \pm 0.10$ \\
\hline 60 & $48.66 \pm 0.25$ & $34.30 \pm 0.15$ \\
\hline 80 & $62.29 \pm 0.29$ & $46.66 \pm 0.21$ \\
\hline 100 & $70.24 \pm 0.27$ & $52.37 \pm 0.06$ \\
\hline 120 & $82.73 \pm 0.35$ & $64.40 \pm 0.15$ \\
\hline
\end{tabular}

Table $\mathbf{5}$ | \% inhibition of nitric oxide radicals by ascorbic acid and MEAP $(n=3)$

\begin{tabular}{ccc}
\hline $\begin{array}{c}\text { Concentration } \\
(\boldsymbol{\mu} \mathbf{g} / \mathrm{ml})\end{array}$ & $\begin{array}{c}\text { Ascorbic acid } \\
(\% \pm \text { SD) }\end{array}$ & $\begin{array}{c}\text { MEAP } \\
(\% \pm \text { SD) }\end{array}$ \\
\hline 20 & $36.92 \pm 0.18$ & $19.40 \pm 0.50$ \\
\hline 40 & $48.90 \pm 0.19$ & $28.84 \pm 0.41$ \\
\hline 60 & $59.52 \pm 0.29$ & $37.25 \pm 0.19$ \\
\hline 80 & $67.54 \pm 0.34$ & $46.24 \pm 0.24$ \\
\hline 100 & $78.85 \pm 0.28$ & $51.58 \pm 0.36$ \\
\hline 120 & $90.17 \pm 0.34$ & $61.27 \pm 0.57$ \\
\hline
\end{tabular}


paracytic stomata (Figure 3). Images of vein islet and vein termination are shown in Figure 4. Powdered microscopic study reveals the presence of covering trichome (Figure 5), spiral vessel (Figure 6), and starch grains (Figure 7) while quantitative microscopic features are given in Figure 8.

\section{Fluorescence analysis}

The powdered drug is olive green in appearance under daylight. The result of the fluorescence analysis of powdered drug is given in Table 1. The results of the fluorescence analysis of extracts are given in Table 2.

\section{Physicochemical parameters}

The results of ash values and extractive values are given in Figures 9 and 10, respectively. A total of $0.12 \pm 0.01 \mathrm{~g}(\mathrm{n}=3)$ of moisture was lost due to drying.

\section{Foreign organic matter}

There were no foreign organic matters present in the collected plant material.

\section{Phytochemical screening}

The results of the preliminary phytochemical screening are given in Table 3.

\section{Thin layer chromatography}

The results of TLC for phenols $\left(R_{f}=0.78\right)$, flavonoids $\left(R_{f}=0.59,0.77,0.86\right)$, glycosides $\left(R_{f}=\right.$ $0.72)$ and steroids $\left(R_{f}=0.86\right)$ are given in Figure 11 .

\section{Total phenol content}

According to the calibration curve given in Figure 12 , the total phenolic content was found to be 33.33 $\pm 0.58 \mathrm{mg}(\mathrm{n}=3)$ of $\mathrm{GAE} / \mathrm{g}$ of the extract.

\section{Total flavonoid content}

According to the calibration curve given in Figure 13 , the total flavonoid content was found to be $20 \pm$ $0.5 \mathrm{mg}(\mathrm{n}=3)$ of $\mathrm{QE} / \mathrm{g}$ of the extract.

\section{2, 2-Diphenyl-1-picrylhyrazyl (DPPH) radical scavenging activity}

The percentage inhibition of quercetin and MEAP is given in Table 4 and a chart representation of the same is given in Figure 14 . The $I C_{50}(\mu \mathrm{g} / \mathrm{ml})$ values of quercetin and MEAP were $64.23 \mu \mathrm{g} / \mathrm{ml}$ and $91.00 \mu \mathrm{g} /$ $\mathrm{ml}$, respectively.

\section{Nitric oxide radical scavenging activity}

The percentage inhibition of the ascorbic acid and MEAPis given in Table 5 and a graphical plot of the same is given in Figure 15. The $1 C_{50}(\mu \mathrm{g} / \mathrm{ml})$ values of ascorbic acid and MEAP were $43.78 \mu \mathrm{g} / \mathrm{ml}$ and $92.66 \mu \mathrm{g} / \mathrm{ml}$, respectively.

Statistical analysis for DPPH radical and nitric oxide radical scavenging activity shows a positive correlation, i.e. percentage inhibition increases with increasing concentration. The correlations for standard and test drugs in both techniques are significant at the 0.01 level respectively.

\section{Discussion}

As part of the characterization process, one of the most reliable standards for identification and authentication of any plant specimen is preestablished standardized pharmacognostic parameters based on which the quality and purity of the crude drug is determined. ${ }^{19}$ This justifies the need to fill up any possible information gap for a proper and systematic development of analytical and diagnostic features of any plant part.

Quantitative microscopic characters like a stomatal number, stomatal index, vein termination number, vein islet number, and palisade ratio given in Figure 8 are unique to each plant species. ${ }^{4}$ The reported aforementioned characters may easily help in validating the identity of the plant specimen from its closely related species.

The research work reports the fluorescence of the powdered crude drug and plant extracts in Tables 1 and 2. Fluorescence study is a helpful tool for checking the presence of adulterants. ${ }^{20}$

Physicochemical parameters like ash values given in Figure 9 reveal the presence of inorganic matter and various impurities such as silica, silicates, carbonates, and phosphates. ${ }^{21}$ This can be used for determining the quality and purity of a crude drug.

Extractive values given in Figure 10 provides an idea regarding the type of compound present in a crude drug and it is also beneficial in terms of retrieving information on the type of compounds soluble in the specific solvent used for extraction. ${ }^{5}$ Following the principle of like dissolves like, it can be concluded that the plant contains more polar compounds as the extractive values are higher for polar solvents.

Preliminary phytochemical screening given in Table 3 is useful for determining the type of organic chemical constituent present. Likewise, it also gives an idea regarding the possible class of bioactive compounds present in the crude drug. ${ }^{5}$ Secondary metabolites with potential medicinal values like flavonoids, phenols, glycosides, and steroids might be indicative of the widespread use of $A$. pennata as 
a medicinal plant.

TLC is an analytical tool used not to conclusively state the presence of phytoconstituents, but rather to give stronger evidence for the presence of phytoconstituents. TLC is a primitive stage in analytical pharmacognosy wherein solvent systems are optimized for HPTLC and other advanced chromatographic techniques. The fingerprint profile developed using TLC as given in Figure 11 can aid in the evaluation, identification and standardization of a crude drug. 4,11

Polyphenolic compounds like phenols and flavonoids have good antioxidant properties. ${ }^{22}$ The methanolic extract of $A$. pennata containing polyphenolic compounds inhibits free radicals in a dose-dependent manner wherein statistical terms, a positive correlation exists between the two variables as given in Figures 14 and 15.

\section{Conclusion}

To avoid any blunder in the form of misidentification of the plant while investigating its potential pharmacological activity, results from the present systematic study may be utilized as a reliable tool to correctly identify and standardize the plant specimen. Additionally, the outcomes of the current study may help draft the herbal monograph of $A$. pennata for effective quality control.

\section{Acknowledgment}

The authors are thankful to the Department of Pharmaceutical Sciences, Dibrugarh University, Dibrugarh 768004, Assam, India for funding and providing the facilities to carry out the research work. The authors are also thankful to the Department of Chemistry, Dibrugarh University, and the Department of Pharmacy, RIPANS, Aizawl, Mizoram, India for providing necessary facilities.

\section{Conflict of interest}

The authors declare no conflict of interest in the paper communicated.

\section{References}

1. Aye, M., Aung, H., Sein, M., Armijos, C. (2019). A review on the phytochemistry, medicinal properties and pharmacological activities of 15 selected Myanmar medicinal plants. Molecules, 24, 1-34. DOI: 10.3390/molecules24020293.

2. Zothantluanga, J.H., Bhat, H.R., Shakya, A. (2019). A systematic review on the nutraceutical potential of Acacia pennata (L.) Willd. Current Trends in Pharmaceutical Research, 6, 12-27.
3. World Health Organization. (2003). WHO guidelines on good agricultural and collection practices for medicinal plants. pp. 7-26.

4. Kokate, C.K., Purohit, A.P., Gokhale, S.B. (2018). Pharmacognosy. Pune, India: Nirali Prakashan, pp. 07.01-07.47.

5. Khandelwal, K.R. (2008). Practical pharmacognosy: techniques and experiments. Maharashtra, India: Nirali Prakashan, pp. 52-160.

6. Evans, W.C., Trease, G.E. (2009). Trease and Evan's pharmacognosy. Singapore: Hartcourt Brace and Company, pp. 226-227.

7. World Health Organization. (1998). Quality control methods for medicinal plant materials. pp. 23-31.

8. Kumar, M., Prasad, S.K., Laloo, D., Joshi, A., Hemalatha, S. (2014). Pharmacognostical and phytochemical standardization of Houttuynia cordata Thunb.: A potent medicinal herb of NorthEastern India and China. Pharmacognosy Journal, 6, 34-42.

9. Thenmozhi, S., Subasini, U., Sathyamurthy, D., Varadharaju, S., Soundappan, K.J. (2012). Pharmacognostic evaluation and phytochemical studies on leaves of Vitex leucoxylon Linn. Pharmacognosy Journal, 4, 16-22. DOI: 10.5530/ pj.2012.31.4.

10. Indian Pharmacopoeia. (2018). Testson herbal products. Uttar Pradesh, India: Indian Pharmacopoeia Commission, 1, 329.

11. Wagner, H., Bladt, S. (2001). Plant drug analysis: A thin layer chromatography atlas. New York, USA: Springer, pp. 99-338.

12. Bhalodia, N., Nariya, P., Acharya, R., Shukla, V. (2011). Evaluation of invitro antioxidant activity of flowers of Cassia fistula Linn. International Journal of Pharmaceutical Technology and Research, 3, 589-599. DOI: 10.5530/ax.2011.1.11.

13. Patel, A., Patel, A., Patel, N.M. (2010). Estimation of flavonoid, polyphenolic content and in vitro antioxidant capacity of leaves of Tephrosia purpurea Linn. (Leguminosae). International Journal of Pharmaceutical Technology and Research, 1, 66-77.

14. Kumar, S., Baskar, T., Shanmugam, S., Rajasekaren, P., Sadasivam, V., Manikandan, V. (2008). Optimization of flavonoids extraction from the leaves of Tabernaemontana heyneana Wall. Using L16 ortho design. Nature and Science, 6, 10-21.

15. Patel, S., Patel, J., Patel, R.K. (2012). To study proximate analysis and biological evaluation of Triphala guggulu formulation. International Journal of Pharmaceutical Technology and Research, 4, 1520- 
1526.

16. Braku, V.Y., Opoku-Boahen, Y., Owusu-Ansah, E., Mensah, E.F. (2013). Antioxidant activity and the estimation of total phenolic and flavonoid contents of the root extract of Amaranthus spinosus. Asian Journal of Plant Science and Research, 3, 69-74.

17. Patel, R.M., Patel, N.J. (2011). In vitro antioxidant activity of coumarin compounds by DPPH, super oxide and nitric oxide free radical scavenging methods. Journal of Advanced Pharmacy Education $\mathcal{E}$ Research, 1, 52-68.

18. Parul, R., Kundu, S.K., Saha, P. (2013). In vitro nitric oxide scavenging activity of methanolic extracts of three Bangladeshi medicinal plants. The Pharma Innovation, 12, 83-88.

19. Upadhya, V., Hegde, H.V., Bhat, S., Hurkadale, P.J., Kholkute, S.D., Hegde, G.R. (2012). Ethnomedicinal plants used to treat bone fracture from North-Central Western Ghats of India. Journal of Ethnopharmacology, 142, 557-562. DOI: 10.1016/j.jep.2012.05.051.
20. Aslam, I., Afridi, M.S. (2017). Pharmacognostic characterization of Beaumontia grandiflora (Roxb.) wall. leaf for taxonomic identification for quality control of a drug. Journal of Applied Research on Medicinal and Aromatic Plants, 8, 53-59. DOI: 10.1016/j.jarmap.2017.11.002.

21. Joshi, B.C., Chauhan, N., Singh, S., Uniyal, S. (2018). Pharmacognostic and phytochemical evaluation of Nyctanthes arbor-tristis stem. International Journal of Pharmacognosy, 5, 376-381. DOI: 10.13040/IJPSR.0975-8232.IJP.5(6).376-81.

22. Subedi, L., Timalsena, S., Duwadi, P., Thapa, R., Paudel, A., Parajuli, K. (2014). Antioxidant activity and phenol and flavonoid contents of eight medicinal plants from Western Nepal. Journal of Traditional Chinese Medicine, 34, 584-590. DOI: 10.1016/s0254-6272(15)30067-4. 